\title{
Clinical Trial, Other
}

National Cancer Institute

\section{Source}

National Cancer Institute. Clinical Trial, Other. NCI Thesaurus. Code C16123.

A clinical trial that is not therapeutic, preventive or diagnostic. 